\title{
Evolution of health care utilization and expenditure during the year before death in 2015 among people with cancer: French snds-based cohort study
}

\author{
Audrey Tanguy-Melac ${ }^{1}$. Dorian Verboux ${ }^{1}$ (I) $\cdot$ Laurence Pestel $^{1}$ - Anne Fagot-Campagna ${ }^{1} \cdot$ Philippe Tuppin $^{1}$. \\ Christelle Gastaldi-Ménager ${ }^{1}$
}

Received: 7 July 2020 / Accepted: 26 March 2021 / Published online: 7 June 2021

(c) The Author(s) 2021

\begin{abstract}
Background Cancer patients have one of the highest health care expenditures (HCE) at the end of life. However, the growth of HCE at the end of life remains poorly documented in the literature.

Objective To describe monthly reimbursed expenditure during the last year of life among cancer patients, by performing detailed analysis according to type of expenditure and the person's age.

Method Data were derived from the Système national des données en santé (SNDS) [national health data system], which comprises information on ambulatory and hospital care. Analyses focused on general scheme beneficiaries ( $77 \%$ of the French population) treated for cancer who died in 2015.

Results Average reimbursed expenditure during the last year of life was $€ 34,300$ per person in 2015, including $€ 21,100$ (62\%) for hospital expenditure. "Short-stays hospital" and "rehabilitation units" stays expenditure were $€ 14,700$ and $€ 2000$, respectively. Monthly expenditure increased regularly towards the end of life, increasing from 12 months before death $€ 2000$ to $€ 52001$ month before death. The highest levels of expenditure did not concern the oldest people, as average reimbursed expenditure was $€ 50,300$ for people 18-59 years versus $€ 25,600$ for people 80-90 years. Out-of-pocket payments varied only slightly according to age, but increased towards the end of life.

Conclusion A marked growth of HCE was observed during the last 4 months of life, mainly driven by hospital expenditure, with a more marked growth for younger people.
\end{abstract}

Keywords End-of-life $\cdot$ Cancer $\cdot$ Healthcare expenditure $\cdot$ France $\cdot$ Out-of-pocket $\cdot$ Administrative database

JEL classification $\mathrm{I} 10 \cdot \mathrm{I} 14 \cdot \mathrm{I} 18$

\section{Introduction}

The sustained growth of health care expenditure (HCE) accentuates the pressure placed on governments, health insurance and individual budgets [1]. Ageing of the population is one of the main drivers of this growth [2]. As highlighted by the World Health Organization, the proportion of the world population aged $60+$ should almost double between 2015 and 2050, and the number of people aged

Dorian Verboux

dorian.verboux@assurance-maladie.fr

1 Caisse Nationale de l'Assurance Maladie (Cnam), 50 avenue du Professeur André Lemierre, 75020 Paris, France
$80+$ should increase almost fourfold over the same period [3]. France is not an exception, as recent demographic estimates show that, by 2070 , there will be 76.5 million inhabitants (+10.7 million people) and that this growth will be essentially due to an increased number of people aged $65+(+10.4$ million $)$ [4].

In their seminal study based on Swiss data, Zweifel et al. (1999) concluded that HCE can be more explained by proximity to death (PTD) (1-2 years before death) than person's age [5]. An equivalent effect were reported in other countries for a panel of health care [2, 6-13]. Even in including 260 morbidities in their estimates, Howdon and Rice (2018) demonstrated an effect of PTD on HCE, although this effect was attenuated when comorbidities were considered [2]. 
As highlighted by the World Health Organization, cancer is the second leading cause of death in the world in 2018. End-of-life people with cancer have a higher HCE than people with other causes of death [14-18]. A study conducted on French administrative data showed that total expenditure for people who died in 2013, all causes combined, was about $€ 17,600^{1}[19]$. The medical spending considered were those during the calendar year of death. In France, the average annual expenditure for cancer patients 1 year before death was estimated at $€ 36,589$ in 2008 [20]. Moreover, spending concentration around several expenditure items has also been studied. For example, in the United States, hospital care accounts for $44.2 \%$ of all expenditure during the last year of life [21]. A recent international comparison of seven countries also showed that people who died from cancer had been frequently hospitalized during the last days of life, regardless health systems or organization of end-of-life care differences from one country to another [22].

Literature concerning the dynamics of end-of-life expenditure remains fairly limited. The majority of studies has reported total expenditure for several time frames before death: the last month, the last 6 months or the last year of life, for example [14, 22, 23]. They thus do not specifically study the month after month dynamics of expenditure during last months of life. Furthermore, most studies focused on only a few expenditure items, most often hospital expenditure. For example, a recent study analyzed the end-of-life expenditure of women with an uterine cancer and they only focused their analyses on hospital expenditure [24]. Another study, based on data derived from a health insurer in The Netherlands, analyzed end-of-life expenditure of people with cancer. Hospital stays represented the leading expenditure, with an average of $€ 12,700$ for the last year of life and $€ 3517$ for the last 30 days of life [25]. Given the high expenses during the last year of life, the question of out-of-pocket (OOP) payments may arise. The few studies conducted showed high OOP payments for people at the end of life [8, 26-28].

The description and analysis of HCE dynamics during the last year of life is an important issue for health insurance. It thus can know the actual costs of cancer at the end-of-life, the intensification of care and the distribution of the expenses among various HCE items. A recent study emphasized the end-of-life hospital-centered approach in France [29] while many studies showed that patients prefer to die at home $[22,30,31]$. As a consequence, description and analysis of end-of-life HCE may help to improve health insurance resources allocation, especially in a context of increasing cancer incidence, while improving accounting patients' wishes.

This article is designed to complete the literature in several ways. First, it aims to analyze the pattern and the evolution of HCE during the last 12 months of life for patient receiving cancer treatment before they died in 2015. Second, the SNDS allows us to distinguish between several expenditure items in both hospital and ambulatory settings. Finally, thanks to this administrative database OOP payments and their evolution during the last year of life are studied. To the best of our knowledge, no existing study has analyzed OOP payments from this point of view.

\section{Data and methods}

\section{Data source}

In France, information concerning the healthcare utilization of the entire French population, i.e. more than 66.6 million people, covered by the various compulsory health insurance schemes, are collected in the Système national des données de santé (SNDS) [national health data system] [32]. It collects anonymous, individualized and comprehensive data concerning all reimbursed private hospitals and outpatient healthcare utilization but also prescriptions and procedures reimbursed (e.g. physicians, dentist, nurses, drugs, transports, etc.). Individuals' information (date of birth, sex, town of residence, etc.) are also available.

All of these data are linked, by using a pseudonymized identifier, to data of the national hospital discharge database (PMSI: programme de médicalisation des systèmes d'information), concerning public stays: short-stay hospitals ("SSH"), rehabilitation units ("Rehab"), hospital-at-home ("HaH") and psychiatric hospitals. Residence in skilled nursing homes (SNH) can also be determined. Drugs given during a hospital stay are directly included in the Diagnosis-Related Group (DRG) tariffs . It is therefore not possible to know precisely which drugs were prescribed and their particular costs. In order to support access to innovation in health care institutions, some innovative drugs or medical devices are registered on a list, called the "liste en sus" which are billable over and above DRG tariffs in short-stay hospitals (SSH). In a synthetic way, SNDS allows us to have information about ambulatory care expenditure and hospitals stays (both public and private sector).

Although, the SNDS does not include clinical data on the results of physician visits, prescriptions or examinations, it however includes information on the presence of one of 30

\footnotetext{
${ }^{1}$ Sum converted with the January 2014 exchange rate and considering inflation up until December 2015 to be consistent with the data presented in this study.
} 
long-term diseases (LTD) eligible for 100\% reimbursement of HCE, including cancer.

\section{Population}

The general health scheme fund has developed algorithms ${ }^{2}$ based on SNDS data to identify beneficiaries who are reimbursed for chronic or serious or expensive diseases each year. These algorithms are mainly based on diagnosis in short-stay hospitals, LTD, specific drugs or procedures. Patients under treatment for cancer one year before their death ("active cancer", hereafter) are thus defined over a 2-years period from SSH (cancer-specific diagnosis, chemotherapy or radiotherapy) and/or new applications for LTD during the last 2 years.

This study encompassed all adults (i.e. aged $18+$ ) who died in 2015 and who were identified as having an active cancer. The population was restricted to beneficiaries of the national health insurance general scheme, because, at this time, the others schemes did not systematically record explicitly the fact that a person was covered by LTD or the vital status of their beneficiaries. In 2015, the general scheme covered about $77 \%$ of the French population.

\section{Analysis}

All total and reimbursed HCE by national health insurance general scheme for each person with at least one health care reimbursement during the year (whether or not this expenditure is related to cancer) were extracted. Total expenditure encompass all expanses presented for reimbursement. Expenditure items costs were available on a monthly basis for all individuals. The following expenditure items were taken into account in the analyses:

- Ambulatory care expenditure: physicians, dentists, paramedical (physiotherapists, nurses, etc.), laboratory tests, drugs (delivered in the pharmacies), medical devices and related services, ${ }^{3}$ transport;

- Hospital expenditure in SSH (including drugs and medical devices out of DRG tariffs), "Rehab", "HaH", psychiatry and outpatient visits and procedures;

- Allowances related to sick leave and disability benefits.

In France, expenditure directly related to LTD (cancer in our case) are totally reimbursed by the general scheme.

\footnotetext{
2 https://www.ameli.fr/l-assurance-maladie/statistiques-et-publicatio ns/etudes-en-sante-publique/cartographie-des-pathologies-et-desdepenses/index.php

${ }^{3}$ Medical devices encompass wheelchairs, medical beds or prostheses for example. Related services are mainly rental packages such as oxygen therapy, insulin pumps, etc.
}

When treatments are not directly related to cancer, $78 \%$ of the expenses are covered by the general scheme, $13 \%$ by complementary health insurance $(\mathrm{CHI})$ and the rest directly by the households on average. Out-of-pocket payments included in this study were calculated as the difference between the amount of expenditure presented for reimbursement and the reimbursed amount by national health insurance general scheme. Out-of-pocket payments, therefore, include all co-payments as well as any excess fees billed by health care professionals. In France, 95\% of the population has access to complementary health insurance [33] and most of these insurances cover a large proportion of co-payments.

For each person, total annual reimbursed expenditure was calculated as the sum of reimbursed expenditure over the last 12 complete months, from month 12 to month 1 , excluding the month of death (month 0 ), which is an extrapolation, submitted to a specific analysis. Expenditure during the last month of life (month 0 ) was treated specifically to allow comparison with the expenditure of the other months. It was extrapolated from the observed expenditure for the days on which the person was alive during this last month divided by the number of days alive, multiplied by 30 .

All statistical analyses were performed with SAS 9.3 software. The CNAM has been granted permanent access to SNDS data by the French data protection agency (CNIL).

\section{Results}

\section{Descriptive statistics}

A total of 125,497 people who died in 2015 with an active cancer were included in the study (Table 1). These people had an average age of $73 \pm 13$ years and $41 \%$ were women. About $18 \%$ had lung cancer and $12 \%$ had colorectal cancer. $52 \%$ of people had cardio-neurovascular disease, $28 \%$ a chronic respiratory disease and $21 \%$ diabetes. All deceased people had at least one hospitalization (SSH, Rehab or $\mathrm{HaH}$ ) during their last year of life (including the month of death). Regardless of age, most people (67\%) died in hospital.

Analyses revealed fairly different results according to age. First, $28 \%$ of our study's population was $80-89$ years, ahead of the 70-79 years age-group which represented $24 \%$ of the study's population. Inversely, less than $10 \%$ of people were aged $90+$. The prevalence of certain cancers also varied considerably according to age group. People who died and who have a lung cancer were younger: $26 \%$ were aged $18-59$, while only $4.5 \%$ were aged $90+$. An opposite trend was observed for prostate cancer: men aged 18-59 represented $1.3 \%$ of the population, while men 90 years and older represented $17 \%$. An increasing prevalence of "cardiovascular and neurovascular disease" and "neurological or degenerative disease" was observed with age. Finally, the 
Table 1 Sociodemographic characteristics at the end of life of patient with cancer who died in 2015, according to age

\begin{tabular}{|c|c|c|c|c|c|c|c|}
\hline \multirow[t]{3}{*}{$N$} & \multirow[b]{2}{*}{ Total } & \multicolumn{6}{|l|}{ Age-group } \\
\hline & & $18-59$ & $60-69$ & $70-79$ & $80-89$ & $\geq 90$ & $p$ \\
\hline & 125,497 & 20,574 & 28,743 & 29,719 & 34,678 & 11,783 & \\
\hline$\%$ & 100 & 16.4 & 22.9 & 23.7 & 27.6 & 9.4 & \\
\hline Women & 41.2 & 43.1 & 35.3 & 37.1 & 44.4 & 53.2 & $* * *$ \\
\hline Mean age (years, mean \pm SD) & $73.0 \pm 13.3$ & $51.7 \pm 7.1$ & $64.9 \pm 2.8$ & $74.7 \pm 2.9$ & $84.3 \pm 2.8$ & $92.7 \pm 2.6$ & $* * *$ \\
\hline $\begin{array}{l}\text { Cardiovascular and neurovascu- } \\
\text { lar disease }\end{array}$ & 51.6 & 27.6 & 42.9 & 54.3 & 64.8 & 69.4 & $* * *$ \\
\hline Diabetes & 21.1 & 10.0 & 20.9 & 26.6 & 24.8 & 16.2 & $* * *$ \\
\hline Mental illness & 7.8 & 11.5 & 8.8 & 6.6 & 6.1 & 6.2 & $* * *$ \\
\hline $\begin{array}{l}\text { Neurological or degenerative } \\
\text { disease }\end{array}$ & 13.1 & 7.1 & 6.1 & 9.9 & 20.1 & 28.4 & $* * *$ \\
\hline Chronic respiratory disease & 27.7 & 25.4 & 31.2 & 30.2 & 26.4 & 21.0 & $* * *$ \\
\hline Chronic inflammatory disease & 3.6 & 3.1 & 3.2 & 3.9 & 4.0 & 3.2 & $* * *$ \\
\hline Rare diseases & 0.8 & 0.7 & 0.8 & 1.0 & 0.8 & 0.3 & $* * *$ \\
\hline HIV/AIDS & 0.5 & 1.6 & 0.5 & 0.2 & 0.1 & 0.1 & $* * *$ \\
\hline Chronic dialysis & 0.9 & 0.5 & 0.8 & 1.2 & 1.1 & 0.5 & $* * *$ \\
\hline Liver or pancreatic disease & 14.0 & 20.3 & 18.7 & 14.7 & 9.0 & 4.8 & $* * *$ \\
\hline Other LTD & 8.7 & 6.8 & 6.5 & 7.9 & 10.6 & 14.1 & $* * *$ \\
\hline \multicolumn{7}{|l|}{ Place of death } & $* * *$ \\
\hline $\mathrm{SSH}$ & 66.9 & 76.6 & 74.6 & 69.9 & 59.4 & 45.9 & \\
\hline $\mathrm{HaH}$ & 4.2 & 4.7 & 4.2 & 4.6 & 3.8 & 3.1 & \\
\hline Rehab & 8.5 & 5.6 & 6.7 & 8.4 & 11.0 & 10.4 & \\
\hline SNH & 5.3 & 0.2 & 1.0 & 2.5 & 8.8 & 21.4 & \\
\hline Other & 15.1 & 13.0 & 13.5 & 14.5 & 16.9 & 19.2 & \\
\hline \multicolumn{8}{|c|}{ At least one stay during the year and mean length of stay, $\%$ (mean number of days \pm SD) } \\
\hline $\mathrm{SSH}$ & $97.6(53 \pm 45)$ & $99.1(66 \pm 51)$ & $99.0(60 \pm 47)$ & $98.4(55 \pm 46)$ & $96.7(43 \pm 39)$ & $91.9(31 \pm 29)$ & $* * *$ \\
\hline $\mathrm{HaH}$ & $10.7(52 \pm 72)$ & $15.6(58 \pm 77)$ & $12.1(54 \pm 72)$ & $11.1(51 \pm 70)$ & $8.0(47 \pm 66)$ & $5.4(47 \pm 74)$ & \\
\hline Rehab & $25.3(52 \pm 54)$ & $16.7(58 \pm 65)$ & $20.1(53 \pm 58)$ & $25.5(52 \pm 55)$ & $32.6(51 \pm 49)$ & $31.5(49 \pm 46)$ & $* *$ \\
\hline All types & $100(70 \pm 66)$ & $100(84 \pm 73)$ & $100(76 \pm 68)$ & $100(73 \pm 67)$ & $100(62 \pm 61)$ & $100(46 \pm 53)$ & $* * *$ \\
\hline SNH & $8.8(174 \pm 118)$ & $0.4(153 \pm 114)$ & $1.9(172 \pm 118)$ & $4.6(164 \pm 119)$ & $14.8(165 \pm 118)$ & $33.4(189 \pm 117)$ & $* * *$ \\
\hline
\end{tabular}

Source: SNDS, All of France, General scheme + SLM

$*_{p}<0.05$

$* * p<0.01$

$* * * p<0.001$

presence of "mental illness", "HIV/AIDS" and "liver and pancreatic diseases" decreased with increasing age.

The places of death differed according to age, although hospitals remained the leading place of death $(67 \%$ of deaths) regardless of age. The youngest people mostly died in SSH (77\%), while the places of death were more varied for the oldest people: $46 \%$ in SSH, $21 \%$ in SNH and $10 \%$ in Rehab. Almost all people (98\%) of the study population, regardless of age, had had at least one SSH stay during the 12 months preceding death. Hospitalization rates varied slightly according to age: $99 \%$ for people aged $18-59$ to $92 \%$ for people aged $90+$. As expected, almost one-third of people aged $90+$ had at least one $\mathrm{SNH}$ stay versus only $0.4 \%$ of people younger than 60 . $\mathrm{HaH}$ rates tended to decline with increasing age (from 15.6 to $5.4 \%)$. 
a: Evolution of monthly total reimbursed expenditure for the main types of HCE (panel A: hospital, panel B: ambulatory care).

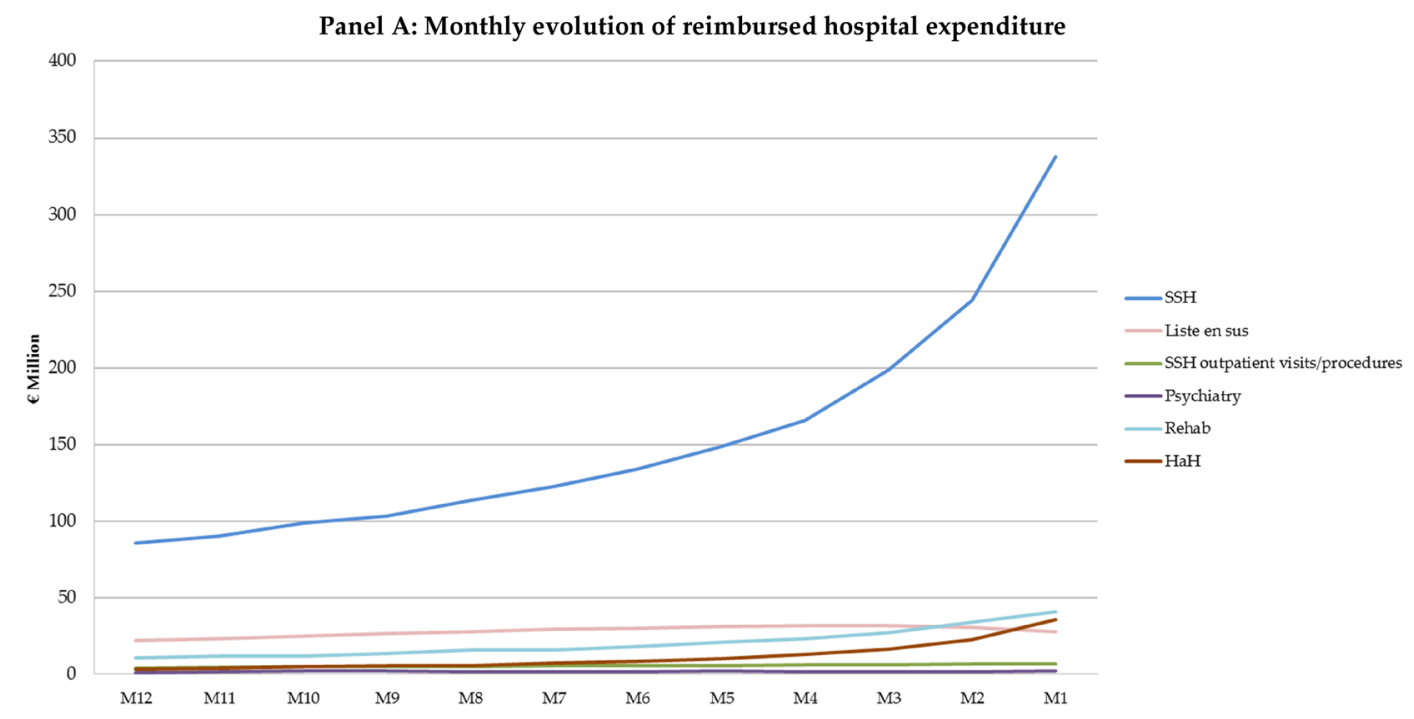

Panel B: Monthly evolution of reimbursed ambulatory care expenditure

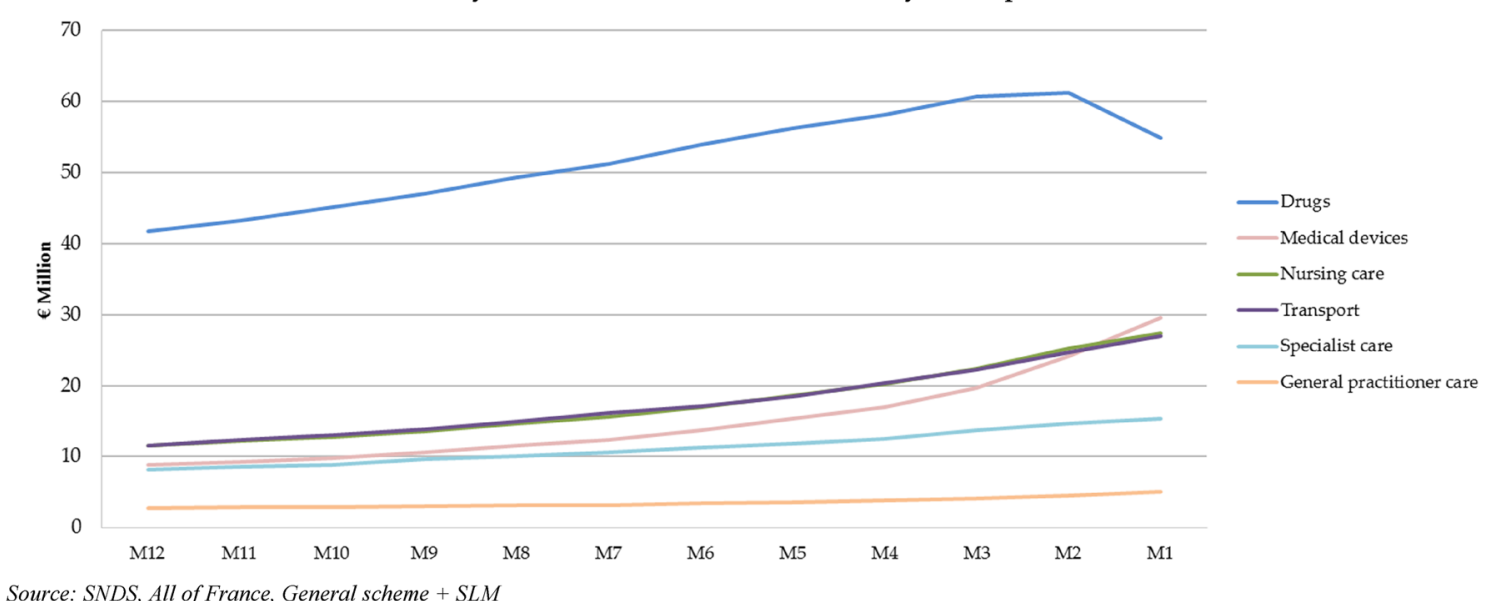

Fig. 1 a Evolution of monthly total reimbursed expenditure for the main types of HCE (panel A: hospital, panel B: ambulatory care). Source: SNDS, all of France, General scheme + SLM. b Evolution of monthly average reimbursed expenditure per patient of the main types of HCE

\section{Total reimbursed expenditure by items and monthly evolution of healthcare utilization rate during the last 12 months of life}

Total reimbursed expenditure for all people who died in 2015 with an active cancer was close to $€ 4.3$ billion (including the month of death, but which was not recalculated) (Supplementary Table S1). About $62 \%$ of this expenditure is for hospital care, $35 \%$ for ambulatory care and 3\% for cash benefits. Expenditure for hospital care and ambulatory care changed dramatically over the last 12 months of life (Fig. 1-Panels A and B). First, SSH expenditure increased relatively linearly between the 12 th month
(M12) and the 4th month (M4) before death. Since M4, SSH expenditure increased dramatically, especially the last month before death. "HaH" expenditure also increased tremendously between M2 and M1. Drugs represented the highest item among ambulatory care expenditure, although drug expenditure decreased sharply between M2 and M1. Marked growth of medical device expenditure was observed throughout the year, especially the last 3 months before death. This expenditure item became the second leading expenditure at M1.

Proportion of patients who used services ("utilization rate", hereafter) increased progressively during the last months of life, regardless expenditure items (Table 2). 
b: Evolution of monthly average reimbursed expenditure per patient of the main types of HCE (panel A: hospital, panel B: ambulatory care).

Panel A: Monthly evolution of reimbursed hospital expenditure

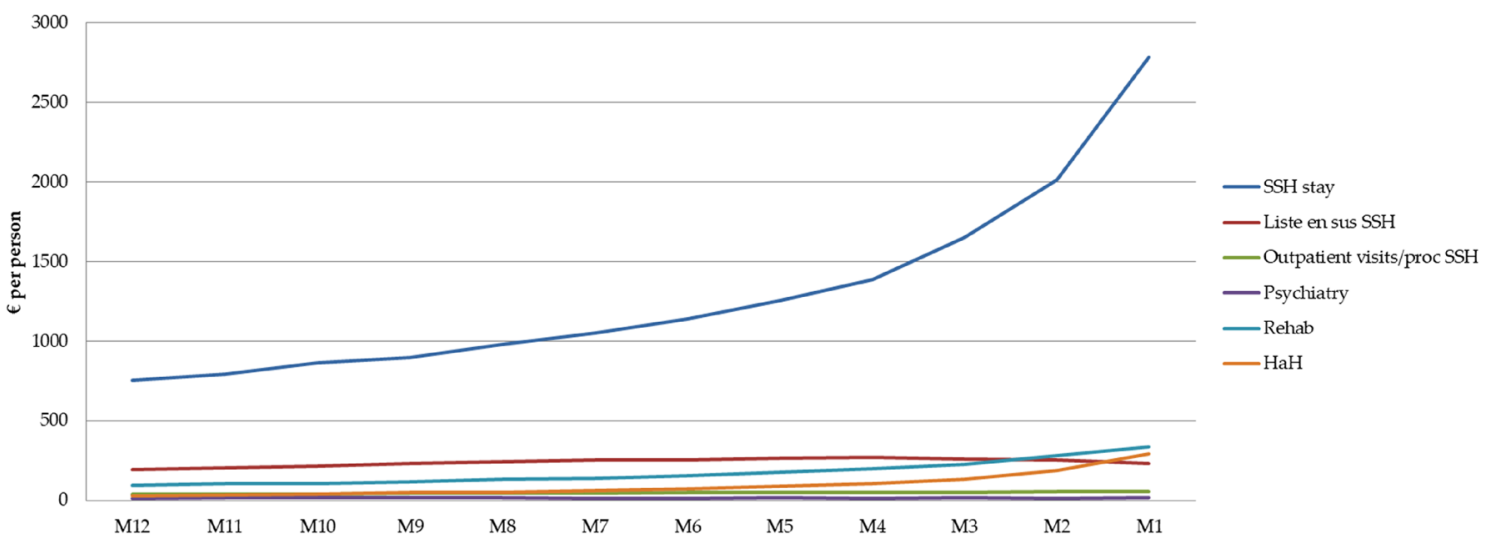

Panel B: Monthly evolution of reimbursed ambulatory care expenditure

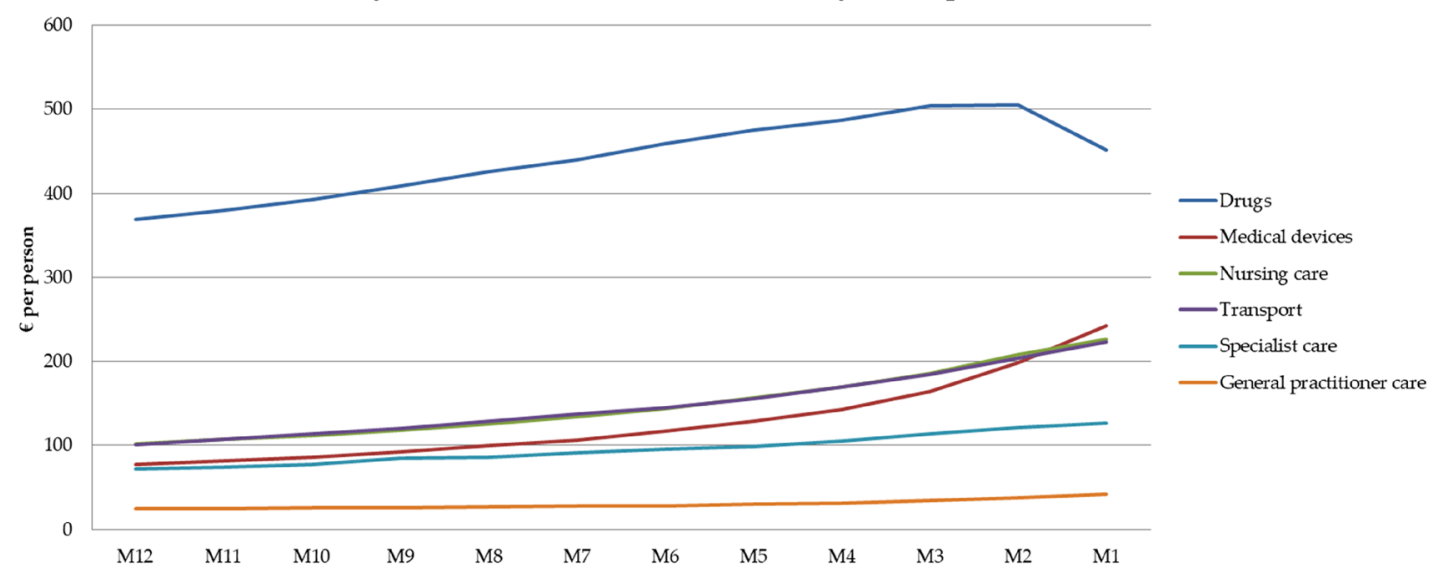

Source: SNDS, All of France, General scheme + SLM

Fig. 1 (continued)

Twelve months before the month of death (M12), $90 \%$ of people had, at least, one health care utilization and this proportion increased to $97 \%$ during M1 (Table 2). This growth of health care utilization rate was mainly related to an increase in hospital stays (increasing from 39\% at M12 to $71 \%$ at M1), particularly SSH stays (increasing from $26 \%$ at M12 to $56 \%$ at M1). Ambulatory care utilization rate also increased, but less than for hospital care. Ambulatory care utilization increased from $89 \%$ at M12 to $93 \%$ at M1, i.e. +4 percentage points $(\mathrm{pp})$ versus $+33 \mathrm{pp}$ for hospital care utilization rate. The highest growth rates were observed for transport and medical devices expenditure, which increased from $27 \%$ at M12 to $62 \%$ at M1 for "transport" and from $34 \%$ at M12 to 55\% at M1 for "medical devices".

\section{Monthly evolution of average reimbursed expenditure during the last 12 months of life}

The last year of life average reimbursed expenditure (excluding M0 expenditure computation) was $€ 34,273$ per patient (Table 3). The average monthly expenditure increased progressively with the PTD from $€ 2021$ (M12) to $€ 5207$ (M1). Extrapolation of the average reimbursed expenditure during the month of the death (M0) was about $€ 24,700$ per patient. Hospital care was the main expenditure item but also the main driver of the increase: hospital care represented 56\% of M12 expenditure but $71 \%$ of M1 expenditure and 93\% of M0 one. Among hospital care expenditure, the highest average expenditure was observed for "SSH stays" with an average expenditure increasing from $€ 756$ (M12) to $€ 2782$ (M1) (+268\%). A sharp growth of average expenditure was also observed for "Rehab" and "HaH". 
Table 2 Evolution of the monthly proportion of individuals using each type of health care expenditure item during the year before death (\% of patients, $n=125,497$ )

\begin{tabular}{|c|c|c|c|c|c|c|c|c|c|c|c|c|c|}
\hline & $\begin{array}{l}\text { M12 } \\
\%\end{array}$ & $\begin{array}{l}\text { M11 } \\
\%\end{array}$ & $\begin{array}{l}\text { M10 } \\
\%\end{array}$ & $\begin{array}{l}\text { M9 } \\
\%\end{array}$ & $\begin{array}{l}\text { M8 } \\
\%\end{array}$ & $\begin{array}{l}\text { M7 } \\
\%\end{array}$ & $\begin{array}{l}\text { M6 } \\
\%\end{array}$ & $\begin{array}{l}\text { M5 } \\
\%\end{array}$ & $\begin{array}{l}\text { M4 } \\
\%\end{array}$ & $\begin{array}{l}\text { M3 } \\
\%\end{array}$ & $\begin{array}{l}\text { M2 } \\
\%\end{array}$ & $\begin{array}{l}\text { M1 } \\
\%\end{array}$ & $\begin{array}{l}\text { M0 } \\
\%\end{array}$ \\
\hline Total reimbursed expenditure & 90.3 & 90.8 & 91.4 & 91.9 & 92.5 & 93.0 & 93.8 & 94.5 & 95.1 & 95.9 & 96.6 & 96.7 & 79.0 \\
\hline Total hospital expenditure & 38.7 & 40.8 & 42.5 & 44.5 & 46.6 & 48.9 & 51.0 & 53.7 & 56.6 & 60.4 & 65.1 & 71.3 & 71.5 \\
\hline SSH stay & 25.6 & 27.2 & 28.9 & 30.5 & 32.7 & 34.6 & 36.6 & 39.1 & 41.7 & 45.3 & 49.8 & 56.3 & 65.8 \\
\hline "Liste en sus" SSH & 7.0 & 7.4 & 7.9 & 8.4 & 8.8 & 9.2 & 9.5 & 9.8 & 10.1 & 10.0 & 9.7 & 9.2 & 7.4 \\
\hline Outpatient visits/proc SSH & 22.2 & 23.5 & 24.1 & 25.2 & 26.0 & 27.0 & 28.0 & 29.0 & 30.3 & 31.5 & 32.7 & 33.1 & 22.4 \\
\hline Psychiatry & 0.1 & 0.2 & 0.1 & 0.2 & 0.1 & 0.1 & 0.2 & 0.2 & 0.2 & 0.2 & 0.1 & 0.2 & 0.1 \\
\hline Rehab & 1.7 & 1.8 & 1.8 & 2.0 & 2.2 & 2.4 & 2.6 & 3.1 & 3.5 & 4.1 & 5.1 & 6.6 & 9.1 \\
\hline $\mathrm{HaH}$ & 0.5 & 0.6 & 0.7 & 0.8 & 0.9 & 1.0 & 1.2 & 1.4 & 1.7 & 2.3 & 3.2 & 5.3 & 9.2 \\
\hline $\begin{array}{l}\text { Total ambulatory care expendi- } \\
\text { ture including }\end{array}$ & 89.3 & 89.8 & 90.4 & 90.9 & 91.4 & 91.9 & 92.6 & 93.3 & 93.7 & 94.3 & 94.5 & 93.2 & 72.6 \\
\hline General practitioner care & 53.0 & 53.7 & 54.4 & 54.9 & 55.6 & 56.5 & 57.2 & 58.1 & 59.2 & 60.5 & 61.2 & 58.7 & 37.5 \\
\hline Specialist care & 29.9 & 30.2 & 30.9 & 31.5 & 32.0 & 32.3 & 32.9 & 33.5 & 34.2 & 34.6 & 34.4 & 31.4 & 13.8 \\
\hline Dental care & 5.1 & 5.1 & 4.9 & 4.7 & 4.7 & 4.5 & 4.5 & 4.2 & 3.9 & 3.4 & 2.8 & 1.9 & 0.5 \\
\hline Physiotherapy & 12.9 & 13.0 & 13.2 & 13.5 & 14.0 & 14.4 & 14.7 & 15.3 & 15.8 & 16.2 & 16.6 & 16.3 & 9.7 \\
\hline Nursing care & 40.1 & 41.3 & 42.7 & 44.0 & 45.5 & 47.1 & 48.6 & 50.1 & 51.6 & 52.9 & 53.4 & 49.5 & 27.5 \\
\hline Laboratory tests & 45.5 & 46.8 & 48.0 & 49.5 & 50.9 & 52.3 & 53.7 & 55.0 & 56.6 & 57.6 & 57.5 & 52.2 & 23.6 \\
\hline Drugs & 82.3 & 82.8 & 83.3 & 83.8 & 84.2 & 84.6 & 84.9 & 85.3 & 85.0 & 84.4 & 82.3 & 74.5 & 40.4 \\
\hline Medical devices & 34.4 & 35.5 & 36.6 & 37.9 & 39.3 & 41.0 & 42.7 & 44.7 & 46.9 & 49.6 & 53.0 & 54.9 & 36.4 \\
\hline Transport & 26.7 & 28.3 & 29.7 & 31.5 & 33.4 & 35.6 & 37.8 & 40.4 & 43.7 & 47.7 & 53.5 & 61.7 & 43.0 \\
\hline Total cash benefits including & 8.2 & 8.4 & 8.6 & 8.8 & 9.1 & 9.4 & 9.6 & 9.9 & 10.2 & 10.5 & 10.8 & 11.0 & 9.4 \\
\hline Sickness benefits & 4.9 & 5.1 & 5.3 & 5.5 & 5.7 & 5.9 & 6.2 & 6.4 & 6.7 & 6.9 & 7.2 & 7.4 & 5.5 \\
\hline Disability benefits & 3.5 & 3.5 & 3.6 & 3.6 & 3.6 & 3.7 & 3.7 & 3.8 & 3.8 & 3.9 & 3.9 & 3.9 & 4.1 \\
\hline
\end{tabular}

Yearly average ambulatory care expenditure was lower than average hospital expenditure ( $€ 11,945$ versus $€ 21,147)$. "Drugs" (prescribed in pharmacies) was the item with the highest average expenditure (about $€ 5000$ per patient), monthly expenditure increasing from $€ 369$ per patient at M12 to $€ 505$ per patient at M2 with a decrease the following months. "Nursing care" and "transport" displayed expenditure of about $€ 1700$ per patient over the 12 months before the month of death. The preponderance of these two expenditure items in the overall average ambulatory expenditure remains relatively constant throughout the last year of life. It is not the case for "medical devices" ( $€ 1449$ per patient over the period) with a monthly average expenditure which increased sharply over the period: $€ 78$ for M12 to $€ 243$ for M1 and $€ 422$ for M0.

\section{Average reimbursed expenditure according to the patient's age and the quarter considered}

Average reimbursed expenditure during the twelve months preceding the month of death tended to decrease as people's age increases (Table 4). Average reimbursed expenditure was slightly more than $€ 50,000$ per patient aged 18-59 and less than $€ 18,000$ per patient for people $90+$. Regardless of age, about $60 \%$ of HCE involved hospital care even though this expenditure decreased markedly with increasing age. Average hospital expenditure for people $18-59$ was close to $€ 30,000$ versus $€ 10,600$ for patients $90+$. In particular, expenditure related to drugs and device out of DRG system ("liste en sus") decreased by more than $90 \%$ (from $€ 5145$ to $€ 360$, per patient). Only "Rehab" item increased with age, from $€ 1496$ for 18-59 years versus $€ 2267$ for people $90+$, per patient. This increase can also be explained by a much higher utilization rate as people's age increases $(12.5 \%$ versus $23 \%$, Table S2). Ambulatory care expenditure growth rate was similar to that observed for hospital care $(€ 15,200$ for 18-59 versus $€ 7000$ for people $90+$ ), but with more marked variations according to expenditure item considered. Average GP expenditure was higher for people 90 + than for people $18-59$ years $(€ 398$ per patient versus $€ 283$ per patient), while average reimbursed specialist expenditure were highest for the youngest patients $(€ 1471$ per patient versus $€ 356$ per patient). Differences in average GP expenditure cannot be explained by differences in the proportion of individuals who have contact with GP (about 
Table 3 Average reimbursed expenditure per patient and per month during the year before death $(€)$

\begin{tabular}{|c|c|c|c|c|c|c|c|c|c|c|c|c|c|c|}
\hline & M12 & M11 & M10 & M9 & M8 & M7 & M6 & M5 & M4 & M3 & M2 & M1 & M0 & Total \\
\hline Average reimbursed expenditure & 2021 & 2122 & 2244 & 2363 & 2523 & 2664 & 2843 & 3068 & 3311 & 3713 & 4267 & 5207 & 24,766 & 34,273 \\
\hline Average hospital expenditure & 1127 & 1196 & 1283 & 1354 & 1467 & 1560 & 1679 & 1846 & 2022 & 2340 & 2802 & 3714 & 22,933 & 21,147 \\
\hline SSH stay & 756 & 793 & 863 & 897 & 981 & 1049 & 1137 & 1253 & 1387 & 1650 & 2013 & 2782 & 18,617 & 14,709 \\
\hline Liste en sus $\mathrm{SSH}$ & 196 & 206 & 217 & 231 & 242 & 252 & 254 & 263 & 268 & 262 & 255 & 230 & 750 & 2698 \\
\hline Outpatient visits/proc SSH & 37 & 40 & 42 & 43 & 45 & 46 & 49 & 50 & 51 & 52 & 54 & 53 & 131 & 528 \\
\hline Psychiatry & 11 & 15 & 17 & 18 & 16 & 14 & 14 & 18 & 13 & 16 & 14 & 19 & 75 & 173 \\
\hline Rehab & 96 & 106 & 103 & 118 & 135 & 136 & 152 & 177 & 197 & 225 & 280 & 337 & 1589 & 1949 \\
\hline $\mathrm{HaH}$ & 31 & 35 & 42 & 48 & 50 & 62 & 73 & 86 & 107 & 134 & 186 & 292 & 1771 & 1091 \\
\hline $\begin{array}{l}\text { Average ambulatory care } \\
\text { expenditure including }\end{array}$ & 804 & 833 & 866 & 910 & 955 & 1000 & 1056 & 1113 & 1176 & 1258 & 1347 & 1380 & 1567 & 11,945 \\
\hline General practitioners & 25 & 25 & 26 & 26 & 27 & 28 & 28 & 30 & 32 & 34 & 37 & 42 & 82 & 338 \\
\hline Specialists & 72 & 75 & 78 & 84 & 86 & 91 & 96 & 99 & 105 & 114 & 121 & 127 & 114 & 1080 \\
\hline Dentists & 4 & 4 & 4 & 3 & 3 & 3 & 3 & 3 & 3 & 2 & 2 & 1 & 1 & 34 \\
\hline Physiotherapists & 21 & 21 & 22 & 22 & 23 & 24 & 25 & 25 & 26 & 27 & 28 & 27 & 24 & 273 \\
\hline Nurses & 102 & 107 & 112 & 118 & 126 & 134 & 144 & 157 & 169 & 186 & 208 & 226 & 255 & 1687 \\
\hline Laboratory tests & 29 & 30 & 31 & 32 & 34 & 35 & 36 & 38 & 39 & 40 & 40 & 37 & 28 & 396 \\
\hline Drugs & 369 & 380 & 393 & 409 & 426 & 439 & 459 & 475 & 486 & 504 & 505 & 452 & 358 & 4972 \\
\hline Medical devices & 78 & 81 & 85 & 92 & 99 & 106 & 117 & 129 & 142 & 164 & 198 & 243 & 422 & 1449 \\
\hline Transport & 101 & 107 & 114 & 121 & 128 & 138 & 145 & 155 & 170 & 185 & 204 & 223 & 250 & 1688 \\
\hline Average cash benefits & 91 & 93 & 95 & 99 & 100 & 104 & 108 & 108 & 114 & 115 & 118 & 113 & 267 & 1181 \\
\hline Sickness benefits & 57 & 59 & 60 & 63 & 65 & 68 & 72 & 72 & 76 & 78 & 80 & 75 & 68 & 776 \\
\hline Disability benefits & 34 & 34 & 35 & 35 & 35 & 35 & 36 & 36 & 37 & 37 & 38 & 38 & 198 & 405 \\
\hline
\end{tabular}

96.5\% for both age groups) but could be due to a greater number of visits. Differences in specialist expenditure could be related to decreasing utilization rate of specialist care with increasing age (87\% versus $75 \%$, for $18-59$ and $90+$ age groups).

Quarterly analysis showed that average reimbursed expenditure tended to increase with the PTD, with the highest expenditure growths observed for SSH, Rehab and $\mathrm{HaH}$. These high expenditure growth rates reflect, among other things, the marked increase in the proportion of patients using this service (Table S2).

\section{Out-of-pocket payments}

Consistent with previous results in terms of average reimbursed expenditure, average out-of-pocket (OOP) increased (Table 5), especially with the PTD. For example, average OOP (all expenditure items considered) for people 60-69 years increased from $€ 300(\mathrm{Q} 4)$ to $€ 583$ (Q1). This OOP growth was essentially due to hospital expenditure, for which OOP increased with time, regardless of age group. Nevertheless, the great majority of OOP's growth rates were lower than those for expenditure.
Furthermore, OOP did not decrease with increasing age, as the average total OOP was $€ 1553$ for the $60-69$ years age group and $€ 1552$ for people $90+$. Consequently, the OOP for the youngest people (who had the highest average expenditure, Table 4) were not much higher than that of the people with the lowest average expenditure. 18-59-yearold individuals had an average expenditure 2.9-fold higher than that of people $90+$, but the OOP ratio was only 1.04 . Furthermore, hospital OOP tended to decrease with age, decreasing from $€ 1038$ for the $18-59$ years age group to $€ 885$ for people $90+$. This declining trend of hospital OOP was parallel to that of total expenditure (Table 4). Inversely, ambulatory care OOP increased with age, in contrast with total expenditure: increasing from $€ 607$ per patient for the 18-59 years age group to $€ 774$ per patient for people 90 years and older.

Analysis of hospital OOP by expenditure item and quarter showed that OOP related to SSH hospitalization varied only slightly during the first three quarters, but then increased considerably during the last quarter. For example, the OOP of people between the ages of 70 and 79 years with at least one SSH stay increased from $€ 213$ to $€ 272$ during the first three quarters to reach $€ 428$ during the last quarter. This increase in OOP during the last quarter can be explained by the marked increase in utilization 


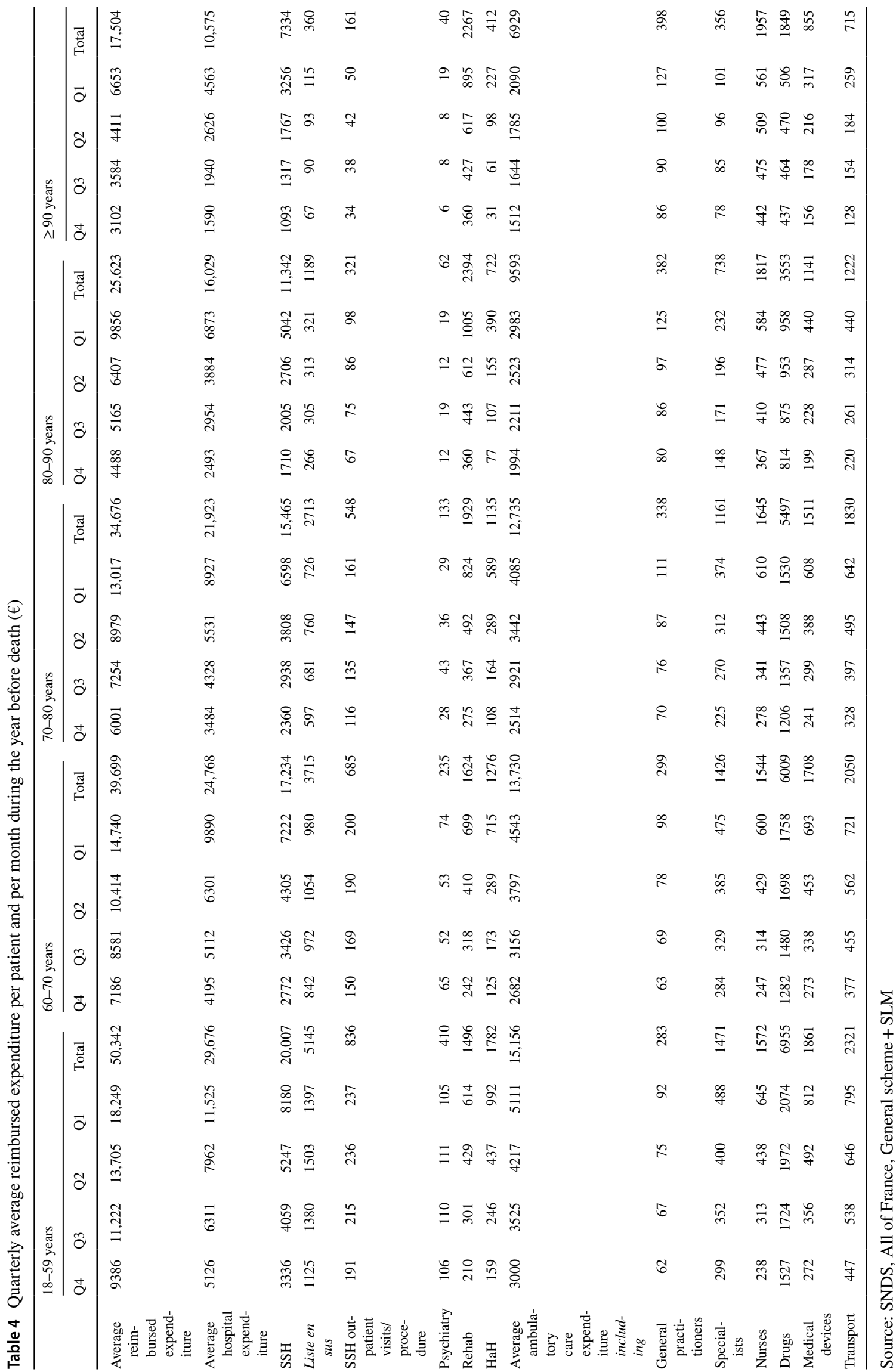




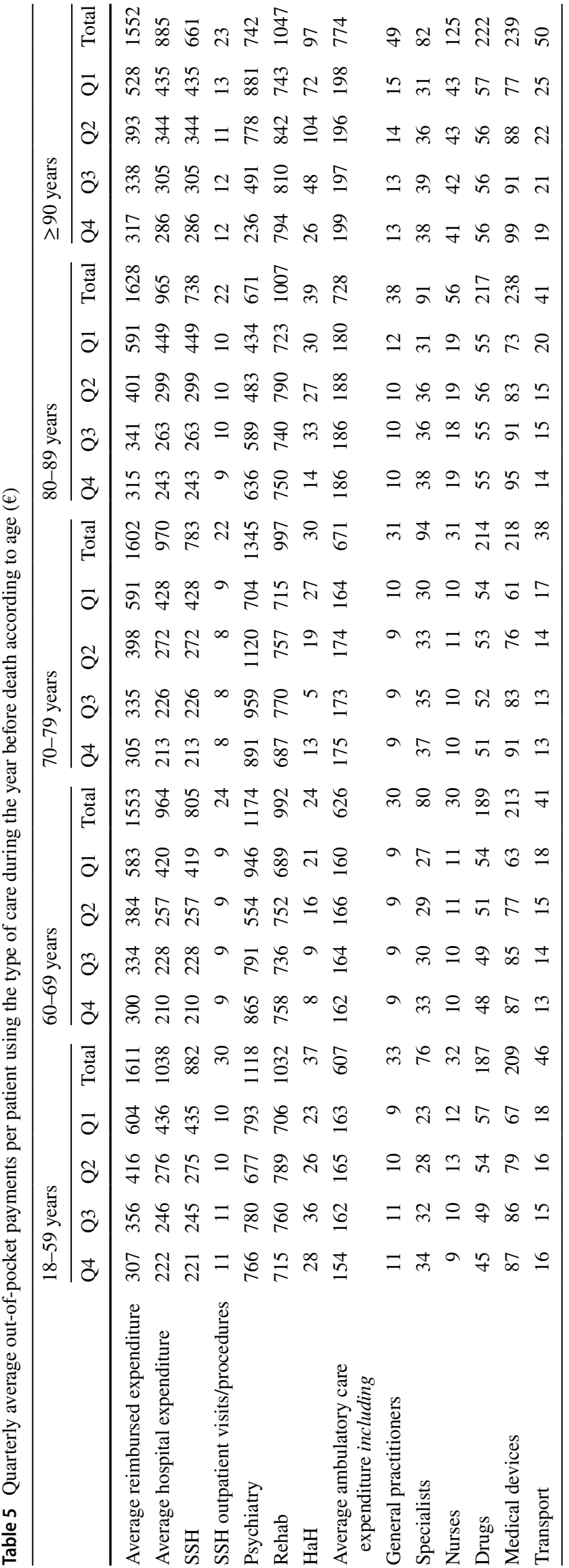

rates during this quarter, regardless of age (Table S2). Ambulatory items with the highest OOP were: "medical devices", "drugs" and "specialists". OOP related to nursing care were particularly high for people 90 years and older. OOP related to "specialists" and "medical devices" decreased throughout the year although, average expenditure increased for each quarter (Table 4). Average OOP related to "drugs" increased during the last quarter for people between the ages of 18 and 79 years, while remained stable throughout the year for people 80 years and older.

\section{Discussion and conclusion}

This study, conducted on SNDS data on 125,000 people treated for cancer and died in 2015, provides detailed information on monthly reimbursed HCE and OOP at the end of life. One of the main strengths of this study is the utilization of SNDS data, ensuring comprehensive data on ambulatory, hospital expenditure and cash benefits [32]. It is thus possible to conduct more detailed analysis in terms of expenditure items where most studies in the literature focus mainly on one care item (drugs, hospitalization, etc.) $[1,2,12,34]$. Moreover, this database encompasses nearly $80 \%$ of the French population. Another strength using SNDS database is that it allows for a long-term follow-up. In addition, the use of medical administrative data considerably limits the risk of memory bias concerning both HCE and OOP. This bias is particularly prevalent in OOP studies because of the frequent use of survey data in this field [8, 26-28].

The results of our study were consistent with those in the literature. First, average reimbursed expenditure over the last 12 months before the month of death in 2015 for people with a cancer was about $€ 34,300$ which was higher than for all French population combined, for which the average expenditure was $€ 17,000$ [19]. However, many studies had shown that end-of-life expenditure of people with cancer are higher than that of people with other diseases [14-16, 35]. Average expenditure may also vary according to the cancer type. Several studies based on the same population and methodology reported specific average expenditure during the last year of life (colorectal: $€ 43,400$, lung: $€ 43,300$, prostate: $€ 38,750$, breast: €45,418) [29, 36, 37]. Our global cancers' HCE are lower than those for specific cancer. In fact, this result is due to the case-mix of cancers in our study population. $40 \%$ of this population is composed of people with cancers with higher expenditure (mainly lung, breast and colorectal cancer) than the average expenditure of people with active cancer. ${ }^{4}$ As a consequence, our average expenditure for all

\footnotetext{
${ }^{4}$ https://www.ameli.fr/l-assurance-maladie/statistiques-et-publicatio ns/etudes-en-sante-publique/cartographie-des-pathologies-et-desdepenses/depenses-remboursees-affectees-a-chaque-pathologie.php
} 
cancers are thus lower than those presented in the others studies.

Second, expenditure increased with PTD, regardless of age, progressively rising from an average monthly expenditure of $€ 2000$ (M12) to $€ 5200$ during the last month before the month of death (M1). This growth of expenditure with the PTD is consistent with the results of the "red herring" literature, which concluded that the high level of HCE was due more to the PTD than to the individual's age per se [6-8]. Third, average end-of-life HCE were lower with increasing age from $€ 50,300$ for people $18-59$ years old to $€ 17,500$ for people $90+$. This result is consistent with several studies conducted in different contexts: England [6], USA [38], The Netherlands [18] and Korea [35]. Finally, HCE towards the end-of-life in France were mainly hospital expenditure. This predominant role of hospital care is also consistent with the results of other studies [22, 24, 25].

In addition to these results, our study provides new insights into the analysis of end-of-life expenditure.

First, medical devices and related services expenditure increased progressively with the PTD. This increase can be the sign of greater use of home support for people at the end of life. Based on the same population, a study pointed out the high utilization rate of medical devices and related services by people predominantly managed at home during their last month of life in 2015 [29]. This increase in medical devices and related services utilization can also reflect patients' preference for death at home [22]. However, as mentioned by Tuppin et al., "among the $20 \%$ of cancer patients treated mainly at home during their last month of life in 2015, almost one-half finally died in hospital shortly after admission"[29]. These results therefore raised the question of the place of palliative care in the end-of-life management of people with cancer, especially as the use of palliative or supportive care in this setting allowed an improvement of the patient's quality of life [39-41].

Second, our results showed that average out-of-pocket payments for people with cancer at the end of life represented between 3 and $9 \%$ of average reimbursed expenditure according to expenditure item. The percentage of out-ofpocket payments increased with age, but the actual sums remained very similar, as the average OOP was $€ 1611$ for people $18-59$ years old vs. $€ 1552$ for people $90+$. Thus, even with a growing amount of HCE, patients faced similar amount of OOP. In France, for most expenditure items (e.g. drugs, biology, most of GP...) OOP consist only of co-payments due to an administered price system. In the same time, individuals with particular expensive pathologies (e.g. cancer, HIV, multiple sclerosis...) can be covered by the long-term disease (LTD) scheme which provides $100 \%$ coverage of co-payments related to the pathology. A great part of patients with cancers are LTD scheme's beneficiaries and thus are covered for cancer-linked co-payments. Even if patients are not LTD scheme's beneficiaries, they can have a complementary health insurance $(\mathrm{CHI})$ which can also covered co-payments. Contrary to LTD beneficiaries, CHI covered patients had to pay an insurance premium. Another part of OOP is extra-billing for health professionals and free selling prices in excess of the statutory tariff. This kind of OOP is not covered by LTD and can be partly or entirely covered by certain $\mathrm{CHI}$, depending of the insurance contract. OOP analyzed in this study are those before $\mathrm{CHI}$ intervention and thus are probably over estimated for the great majority of the patients. Despite the LTD scheme and the possibility to have a CHI, very high concentration of OOP are likely to occur [42]. However, thanks to all these schemes, France has one of the lowest levels of out-of-pocket payments of all OECD countries, accounting for about $10 \%$ of total HCE. ${ }^{5}$ France is therefore the country with the second lowest percentage of OOP after South Africa (7.7\% in 2015), with a much lower rate than in countries such as Australia (19\%) or Korea (34\%).

Our comprehensive data allow analyzing a specific item expenditure which is drugs and medical devices out DRG tariffs that promotes access to innovative devices. Results clearly indicate an item's expenditure growth in PTD but average expenditure was lower as patients' age increased. This important difference may be the consequence, on one hand, of marked disparities in the utilization rate of innovative drugs and medical devices according to age. Indeed, the utilization rate for this expenditure item is $10.2 \%$ for people $90+$ versus more than $45 \%$ for $18-59$ years (Table S2). These results may raise the question of equal access to innovative drugs and medical devices even in a fully reimbursement scheme. A recent study analyzed all incident cases of metastatic lung cancer hospitalized for a chemotherapy in public hospitals in 2011 and their access to innovative drugs [43]. They showed that the probability of prescription of innovative drugs is inversely related to age. Similar results are also found in different contexts [44]. On the other hand, older individuals may have more comorbidities or be diagnosed later, because they are no longer in the organized screening age groups, which may contraindicate the use of these innovative drugs.

This study has several limitations. First, this study was based on administrative reimbursement data; coding errors are therefore always possible. Furthermore, data are only available for general scheme beneficiaries and for reimbursements for people treated for their cancer. Their causes of death are in the process of being included in the SNDS and could be linked for $94 \%$ of them. Based on the same population, $81 \%$ of patients had a tumor as the main cause of death [45]. However, as we did not focus on cancer-specific HCE,

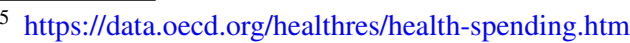


there may be no concern about global HCE for the rest of the population. Failure to take into account nursing home expenditure may have artificially accentuated the decline in expenditure over the 12 months before the death of the oldest people, as the proportion of institutionalized people increased with age. However, as only a small proportion of people, about $5 \%$, were institutionalized, nursing home expenditure would consequently not have been sufficient to reverse the overall trend [46]. In 2015, the general scheme covered $77 \%$ of the French population. The rest is covered by other compulsory health insurance schemes (mainly farmers, self-employed, civil servants or students) and was beyond the scope of this study. No information concerning private health insurance was available. Consequently, the OOP presented here may have been partially or fully reimbursed by private health insurance, which would further reduce the real OOP. Our dataset did not encompass expenditure items that are not covered by the general scheme. As a result, a part of the actual total expenses financed by CHI or directly by individuals are not available in our data. The M0 may be overestimated if people presented on only 1 day in the month had particularly large expenses on that day alone. Nevertheless, the same applied for individuals with very low expenses on that day. Moreover, individuals in the last month are presented in average 14 days. We can thus assume a twofold overestimation.

Despite these limitations, our study provides interesting information for decision makers. In particular, the French LTD system allows a $100 \%$ coverage of cancer-related HCE and thus limits the amount of OOP. This scheme ensures a very good coverage of expenses directly related to cancer. Moreover, OOP can be partially or completely covered, depending of the CHI's contract. Despite this system, individual disparities may exist, with possible dramatic OOP for some person, which should be studied more specifically. In the same way, further studies on disparities in the use of innovations and the place/impact of palliative care near to death for people with cancer would be interesting in order to help policy maker to provide a more efficient access to this type of care.

Supplementary Information The online version contains supplementary material available at https://doi.org/10.1007/s10198-021-01304-1.

Open Access This article is licensed under a Creative Commons Attribution 4.0 International License, which permits use, sharing, adaptation, distribution and reproduction in any medium or format, as long as you give appropriate credit to the original author(s) and the source, provide a link to the Creative Commons licence, and indicate if changes were made. The images or other third party material in this article are included in the article's Creative Commons licence, unless indicated otherwise in a credit line to the material. If material is not included in the article's Creative Commons licence and your intended use is not permitted by statutory regulation or exceeds the permitted use, you will need to obtain permission directly from the copyright holder. To view a copy of this licence, visit http://creativecommons.org/licenses/by/4.0/.

\section{References}

1. Moore, P.V., Bennett, K., Normand, C.: Counting the time lived, the time left or illness? Age, proximity to death, morbidity and prescribing expenditures. Soc. Sci. Med. 184, 1-14 (2017). https:// doi.org/10.1016/j.socscimed.2017.04.038

2. Howdon, D., Rice, N.: Health care expenditures, age, proximity to death and morbidity: implications for an ageing population. J. Health Econ. 57, 60-74 (2018). https://doi.org/10.1016/j.jhealeco. 2017.11.001

3. World Health Organization: World report on ageing and health, (2015)

4. Blanpain, N., Buisson, G.: Projections de population à l'horizon 2070, Insee Premières (2016). https://www.insee.fr/fr/statistiqu es/2496228

5. Zweifel, P., Felder, S., Meiers, M.: Ageing of population and health care expenditure: a red herring? Health Econ. 8, 485-496 (1999). https://doi.org/10.1002/(sici)1099-1050(199909)8:6\% 3c485::aid-hec461\%3e3.0.co;2-4

6. Hazra, N.C., Rudisill, C., Gulliford, M.C.: Determinants of health care costs in the senior elderly: age, comorbidity, impairment, or proximity to death? Eur. J. Health Econ. 19, 831-842 (2018). https://doi.org/10.1007/s10198-017-0926-2

7. von Wyl, V., Telser, H., Weber, A., Fischer, B., Beck, K.: Cost trajectories from the final life year reveal intensity of end-of-life care and can help to guide palliative care interventions. BMJ Support. Palliat. Care. 8, 325-334 (2018). https://doi.org/10.1136/bmjsp care-2014-000784

8. Penders, Y.W., Rietjens, J., Albers, G., Croezen, S., Van den Block, L.: Differences in out-of-pocket costs of healthcare in the last year of life of older people in 13 European countries. Palliat. Med. 31, 42-52 (2017). https://doi.org/10.1177/0269216316647206

9. Werblow, A., Felder, S., Zweifel, P.: Population ageing and health care expenditure: a school of "red herrings"? Health Econ. 16, 1109-1126 (2007). https://doi.org/10.1002/hec.1213

10. Felder, S., Werblow, A., Zweifel, P.: Do red herrings swim in circles? Controlling for the endogeneity of time to death. J. Health Econ. 29, 205-212 (2010). https://doi.org/10.1016/j.jhealeco.2009.11.014

11. Wong, A., van Baal, P.H.M., Boshuizen, H.C., Polder, J.J.: Exploring the influence of proximity to death on disease-specific hospital expenditures: a carpaccio of red herrings. Health Econ. 20, 379-400 (2011). https://doi.org/10.1002/hec.1597

12. Moore, P.V., Bennett, K., Normand, C.: The importance of proximity to death in modelling community medication expenditures for older people: evidence from New Zealand. Appl. Health Econ. Health Policy. 12, 623-633 (2014). https://doi.org/10.1007/ s40258-014-0121-x

13. Yu, T.H.-K., Wang, D.H.-M., Wu, K.-L.: Reexamining the red herring effect on healthcare expenditures. J. Bus. Res. 68, 783787 (2015). https://doi.org/10.1016/j.jbusres.2014.11.028

14. Langton, J.M., Srasuebkul, P., Haas, M., Viney, R., Currow, D., Pearson, S.-A.: Health service use and costs in the last 6 months of life in elderly decedents with a history of cancer: a comprehensive analysis from a health payer perspective. Br. J. Cancer. 114, 1293-1302 (2016). https://doi.org/10.1038/bjc.2016.75

15. Tangka, F.K.L., Subramanian, S., Sabatino, S.A., Howard, D.H., Haber, S., Hoover, S., Richardson, L.C.: End-of-life medical 
costs of medicaid cancer patients. Health Serv. Res. 50, 690-709 (2015). https://doi.org/10.1111/1475-6773.12259

16. Chastek, B., Harley, C., Kallich, J., Newcomer, L., Paoli, C.J., Teitelbaum, A.H.: Health care costs for patients with cancer at the end of life. J. Oncol. Pract. 8, 75s-80s (2012). https://doi.org/ 10.1200/JOP.2011.000469

17. Gielen, B., Remacle, A., Mertens, R.: Patterns of health care use and expenditure during the last 6 months of life in Belgium: differences between age categories in cancer and non-cancer patients. Health Policy Amst. Neth. 97, 53-61 (2010). https://doi.org/10. 1016/j.healthpol.2010.03.002

18. Polder, J.J., Barendregt, J.J., van Oers, H.: Health care costs in the last year of life-the Dutch experience. Soc. Sci. Med. 63, 1720 1731 (2006). https://doi.org/10.1016/j.socscimed.2006.04.018

19. Gastaldi-Ménager, C., Geoffard, P.-Y., de Lagasnerie, G.: Medical spending in France: concentration, persistence and evolution before death: medical spending in France. Fisc. Stud. 37, 499-526 (2016). https://doi.org/10.1111/j.1475-5890.2016.12107

20. Ricci, P., Mezzarobba, M., Blotière, P.O., Polton, D.: Reimbursed health expenditures during the last year of life, in France, in the year 2008. Rev. Epidemiol. Sante Publique. 61, 29-36 (2013). https://doi.org/10.1016/j.respe.2012.04.007

21. French, E.B., McCauley, J., Aragon, M., Bakx, P., Chalkley, M., Chen, S.H., Christensen, B.J., Chuang, H., Côté-Sergent, A., De Nardi, M., Fan, E., Échevin, D., Geoffard, P.-Y., GastaldiMénager, C., Gørtz, M., Ibuka, Y., Jones, J.B., Kallestrup-Lamb, M., Karlsson, M., Klein, T.J., de Lagasnerie, G., Michaud, P.-C., O’Donnell, O., Rice, N., Skinner, J.S., van Doorslaer, E., Ziebarth, N.R., Kelly, E.: End-of-life medical spending in last twelve months of life is lower than previously reported. Health Aff. Proj. Hope. 36, 1211-1217 (2017). https://doi.org/10.1377/hlthaff. 2017.0174

22. Bekelman, J.E., Halpern, S.D., Blankart, C.R., Bynum, J.P., Cohen, J., Fowler, R., Kaasa, S., Kwietniewski, L., Melberg, H.O., Onwuteaka-Philipsen, B., Oosterveld-Vlug, M., Pring, A., Schreyögg, J., Ulrich, C.M., Verne, J., Wunsch, H., Emanuel, E.J.: For the international consortium for end-of-life research (ICELR): comparison of site of death, health care utilization, and hospital expenditures for patients dying with cancer in 7 developed countries. JAMA 315, 272 (2016). https://doi.org/10.1001/jama.2015.18603

23. Lee, C.-C., Chang, T.-S., Wu, C.-J., Yang, C.-C., Chen, P.-C.: Determinants of end-of-life expenditures in patients with oral cancer in Taiwan: a population-based study. PLoS ONE 10, e0126482 (2015). https://doi.org/10.1371/journal.pone.0126482

24. Margolis, B., Chen, L., Accordino, M.K., Clarke Hillyer, G., Hou, J.Y., Tergas, A.I., Burke, W.M., Neugut, A.I., Ananth, C.V., Hershman, D.L., Wright, J.D.: Trends in end-of-life care and health care spending in women with uterine cancer. Am. J. Obstet. Gynecol. 217(434), e1-434.e10 (2017). https://doi.org/10.1016/j.ajog.2017.07.006

25. van der Plas, A.G., Oosterveld-Vlug, M.G., Pasman, H.R.W., Onwuteaka-Philipsen, B.D.: Relating cause of death with place of care and healthcare costs in the last year of life for patients who died from cancer, chronic obstructive pulmonary disease, heart failure and dementia: a descriptive study using registry data. Palliat. Med. 31, 338-345 (2017). https://doi.org/10.1177/0269216316685029

26. Kelley, A.S., McGarry, K., Fahle, S., Marshall, S.M., Du, Q., Skinner, J.S.: Out-of-pocket spending in the last five years of life. J. Gen. Intern. Med. 28, 304-309 (2013). https://doi.org/10.1007/ s11606-012-2199-x

27. Marshall, S., McGarry, K., Skinner, J.: The risk of out-of-pocket health care expenditure at end of life. National Bureau of Economic Research, Cambridge (2010)

28. Orlovic, M., Marti, J., Mossialos, E.: Analysis of end-of-life care, out-of-pocket spending, and place of death in 16 European countries and Israel. Health Aff. 36, 1201-1210 (2017). https://doi.org/ 10.1377/hlthaff.2017.0166
29. Tuppin, P., Tanguy-Melac, A., Lesuffleur, T., Janah, A., GastaldiMénager, C., Fagot-Campagna, A.: Intensity of care for cancer patients treated mainly at home during the month before their death: an observational study. Presse Med. 48, e293-e306 (2019). https://doi.org/10.1016/j.lpm.2019.09.044

30. De Roo, M.L., Miccinesi, G., Onwuteaka-Philipsen, B.D., Van Den Noortgate, N., Van den Block, L., Bonacchi, A., Donker, G.A., Lozano Alonso, J.E., Moreels, S., Deliens, L., Francke, A.L.: EURO IMPACT: actual and preferred place of death of home-dwelling patients in four European countries: making sense of quality indicators. PLoS ONE 9, e93762 (2014). https://doi.org/ 10.1371/journal.pone.0093762

31. Gomes, B., Higginson, I.J., Calanzani, N., Cohen, J., Deliens, L., Daveson, B.A., Bechinger-English, D., Bausewein, C., Ferreira, P.L., Toscani, F., Meñaca, A., Gysels, M., Ceulemans, L., Simon, S.T., Pasman, H.R.W., Albers, G., Hall, S., Murtagh, F.E.M., Haugen, D.F., Downing, J., Koffman, J., Pettenati, F., Finetti, S., Antunes, B., Harding, R.: PRISMA: preferences for place of death if faced with advanced cancer: a population survey in England, Flanders, Germany, Italy, the Netherlands, Portugal and Spain. Ann. Oncol. Off. J. Eur. Soc. Med. Oncol. 23, 2006-2015 (2012). https://doi.org/10.1093/annonc/mdr602

32. Tuppin, P., Rudant, J., Constantinou, P., Gastaldi-Ménager, C., Rachas, A., de Roquefeuil, L., Maura, G., Caillol, H., Tajahmady, A., Coste, J., Gissot, C., Weill, A., Fagot-Campagna, A.: Value of a national administrative database to guide public decisions: from the système national d'information interrégimes de l'Assurance Maladie (SNIIRAM) to the système national des données de santé (SNDS) in France. Rev. DÉpidémiologie Santé Publique. 65, S149S167 (2017). https://doi.org/10.1016/j.respe.2017.05.004

33. Pierre, A., Jusot, F., Raynaud, D., Franc, C.: Généralisation de la complémentaire santé d'entreprise: une évaluation ex ante des gains et des pertes de bien-être. Rev. Économique. 69, 407 (2018). https://doi.org/10.3917/reco.693.0407

34. Geue, C., Briggs, A., Lewsey, J., Lorgelly, P.: Population ageing and healthcare expenditure projections: new evidence from a time to death approach. Eur. J. Health Econ. 15, 885-896 (2014). https://doi.org/10.1007/s10198-013-0543-7

35. Hwang, I., Shin, D.W., Kang, K.H., Yang, H.K., Kim, S.Y., Park, J.-H.: Medical costs and healthcare utilization among cancer decedents in the last year of life in 2009. Cancer Res. Treat. 48, 365-375 (2016). https://doi.org/10.4143/crt.2014.088

36. Tanguy-Melac, A., Aguade, A., Fagot-Campagna, A., GastaldiMénager, C., Sabaté, J., Tuppin, P.: Management and intensity of medical end-of-life care in people with colorectal cancer during the year before their death in 2015: a French national observational study. Cancer Med. 8, 6671-6683 (2019). https://doi.org/ 10.1002/cam4.2527

37. Tanguy-Melac, A., Lesuffleur, T., Fagot-Campagna, A., GastaldiMénager, C., Rébillard, X., Tuppin, P.: Health care utilization by men with prostate cancer during the year before their death: A 2015 population-based study. Progres En Urol. J. Assoc. Francaise Urol. Soc. Francaise Urol. 29, 995-1006 (2019). https://doi.org/ 10.1016/j.purol.2019.09.006

38. Neuman, P., Cubanski, J., Damico, A.: Medicare per capita spending by age and service: new data highlights oldest beneficiaries. Health Aff. 34, 335-339 (2015). https://doi.org/10.1377/hlthaff. 2014.1371

39. Hung, Y.-N., Wen, F.-H., Liu, T.-W., Chen, J.-S., Tang, S.T.: Hospice exposure is associated with lower health care expenditures in Taiwanese cancer decedents' last year of life: a population-based retrospective cohort study. J. Pain Symptom Manage. 55, 755-765. e5 (2018). https://doi.org/10.1016/j.jpainsymman.2017.10.010

40. Kavalieratos, D., Corbelli, J., Zhang, D., Dionne-Odom, J.N., Ernecoff, N.C., Hanmer, J., Hoydich, Z.P., Ikejiani, D.Z., KleinFedyshin, M., Zimmermann, C., Morton, S.C., Arnold, R.M., Heller, 
L., Schenker, Y.: Association between palliative care and patient and caregiver outcomes: a systematic review and meta-analysis. JAMA 316, 2104 (2016). https://doi.org/10.1001/jama.2016.16840

41. Nevadunsky, N.S., Gordon, S., Spoozak, L., Van Arsdale, A., Hou, Y., Klobocista, M., Eti, S., Rapkin, B., Goldberg, G.L.: The role and timing of palliative medicine consultation for women with gynecologic malignancies: association with end of life interventions and direct hospital costs. Gynecol. Oncol. 132, 3-7 (2014). https://doi.org/10.1016/j.ygyno.2013.10.025

42. HCAAM: Rapport annuel, (2013). https://www.securite-socia le.fr/home/hcaam/zone-main-content/rapports-et-avis-1/rapportannuel-2013.html

43. Scherpereel, A., Durand-Zaleski, I., Cotté, F.-E., Fernandes, J., Debieuvre, D., Blein, C., Gaudin, A.-F., Tournier, C., Vainchtock, A., Chauvin, P., Souquet, P.-J., Westeel, V., Chouaïd, C.: Access to innovative drugs for metastatic lung cancer treatment in a French nationwide cohort: the TERRITOIRE study. BMC Cancer 18, 1013 (2018). https://doi.org/10.1186/s12885-018-4958-5
44. Patel, N., Adatia, R., Mellemgaard, A., Jack, R., Møller, H.: Variation in the use of chemotherapy in lung cancer. Br. J. Cancer. 96, 886-890 (2007). https://doi.org/10.1038/sj.bjc.6603659

45. Tanguy-Melac, A., Lesuffleur, T., Bousquet, P.-J., Fagot-Campagna, A., Gastaldi-Ménager, C., Tuppin, P.: Cancer and end of life: the management provided during the year and the month preceding death in 2015 and causes of death in France. Support. Care Cancer. (2019). https://doi.org/10.1007/s00520-019-05188-Z

46. Levinsky, N.G.: Influence of age on medicare expenditures and medical care in the last year of life. JAMA 286, 1349 (2001). https://doi.org/10.1001/jama.286.11.1349

Publisher's Note Springer Nature remains neutral with regard to jurisdictional claims in published maps and institutional affiliations. 